\title{
CORRESPONDENCE
}

\section{The market value of GM products}

\section{To the Editor:}

I am writing to point out that the Data Page published in the March issue ${ }^{1}$ substantially underestimates the market value of transgenic crops. Using a more accurate estimate dramatically changes the fraction of US gross domestic product (GDP) that can be attributed to genetically modified (GM) systems.

According to the International Service for the Acquisition of Agri-biotech Applications (ISAAA; New York), the data displayed in the upper left graph on $p$. 221 is explicitly from seeds and licensing revenues rather than from 'crops', which have much greater market value. Worldwide farm-scale revenues from GM crops are difficult to assess directly, but good data are available for the United States. The Economic Research Service reports that $80-90 \%$ of all corn, soy, and cotton grown in the United States is transgenenic (http://www.ers.usda.gov/ Data/BiotechCrops/), whereas the National Agriculture Statistics Service (NASS) reports total revenues for these crops at more than $\$ 110$ billion (http://www.nass. usda.gov/Data_and_Statistics/Quick_Stats/ index.asp). Taken together, the reports enable an estimation of the revenues from the major GM crops at about $\$ 65$ billion in 2008 (Fig. 1). The data demonstrate substantial fluctuations in revenues due to changes in annual prices, even as the fraction of GM crops planted continues to increase. The ISAAA reports that about half of all transgenic seeds were planted in the United States ${ }^{2}$, and if one assumes that prices paid for crops in the United States are representative of global averages, then global farm-scale revenues from GM corn, soy and cotton in 2008 were about $\$ 130$ billion.

Combining these adjusted crop revenue figures with contributions from GM drugs ('biologics') and GM industrial products (fuels, materials, enzymes) that I have previously estimated ${ }^{3}$ reveals that US revenues from GM products were $\sim \$ 240$ billion in 2007 and are growing at 15-20\%

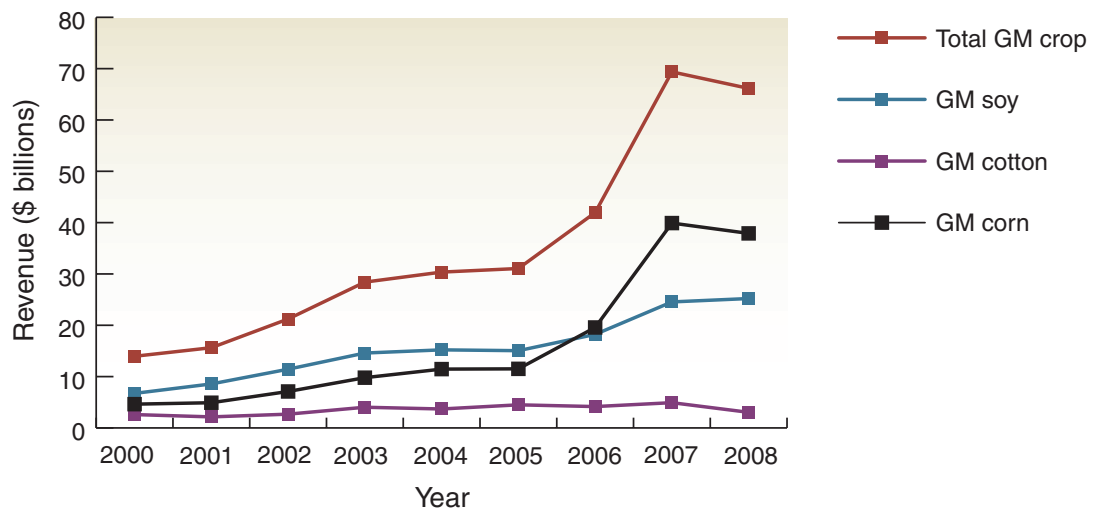

Figure 1 US Revenues from major GM crops.

annually. Given the predicted stagnant US GDP, which is estimated at about $\$ 14.3$ trillion in 2008, revenues from GM systems could amount to the equivalent of about $2 \%$ of US GDP in 2009.

Rob Carlson
Biodesic, Seattle, Washington, USA.

e-mail:rob@biodesic.com

1. Marshall, A. Nat. Biotechnol. 27, 221 (2009).

2. James, C. Global Status of Commercialized Biotech/GM Crops: 2008, International Service for the Acquisition of Agri-biotech Applications. ISAAA Brief No. 39 (ISAAA: Ithaca, NY, 2009).

3. Carlson, R. Syst. Synth. Biol. 1, 109-117 (2007).

\section{Accreditation and attribution in data sharing}

\section{To the Editor:}

In the editorial in your June issue 'Credit where credit is overdue ${ }^{1}$, discussing obstacles to sharing of research data, you highlight accreditation to researchers who deposit their data in public archives as an important incentive strategy. Treating data as publications and leveraging peer recognition to motivate data sharing is key to tackling numerous issues surrounding research data availability ${ }^{2,3}$. As you point out, digital object identifiers (DOIs) can be recruited to identify published data sets. Such an approach has been piloted for several years in a limited number of scientific domains and efforts are now ongoing to widen the scope of 'data DOIs' to other kinds of research data. But several long- and short-term obstacles will have to be overcome if data sets are to become first-class, citable citizens of the scientific literature.

DOIs and other persistent identifier schemes address the nagging problem of Web hyperlink decay or 'link rot' in the literature, resulting from citations to Internet references ${ }^{4}$. In the scholarly and professional publishing domain, CrossRef (http://www.crossref.org/), a not-for-profit association comprising over 700 publishers, libraries and other stakeholders, provides technological and social infrastructure which supports identifying, locating and citing publications via DOIs.

Although efforts to leverage the benefits of DOIs as persistent identifiers of data sets 